\title{
Når døde børn er livets gave Unisex moderskab og organdonation i USA
}

\section{Af Anja Marie Bornø Jensen}

Det er kvinder, isar mødre til organdonover, der gennem en serlig praktisering af "moderskab" satter dagsordenen for den organisatoriske stotte og opfolgning, der tilbydes alle pairorende til organdonorer $i$ USA $i$ tiden efter samtykket til organdonation. Men bvordan kommer dette partikulare moderskab til udtryk, og bvilke implikationer har det for mandene?
I

USA findes en velorganiseret og værdiladet opfølgning og støtte til sørgende pårørende, der har samtykket til donation af deres familiemedlems organer. Denne organisatoriske interaktion er domineret af kvinder, primært mødre, der har mistet et barn. Mange af disse mødre er særdeles aktive og involverede og kommer dermed til at sætte en kønnet dagsorden for, hvordan det at være pårørende til en organdonor struktureres og praktiseres i en organisatorisk kontekst. Mænd bliver ofte fastholdt i rollen som enten tavse og udeltagende $\mathrm{i}$ organisationens aktiviteter, eller som deltagende på kvindernes præmisser. Kvindernes organisatoriske dominans i denne særlige kontekst kan ses som endnu et eksempel på amerikanske kvinders stærke engagement $i$ frivillige aktiviteter, men adskiller sig samtidig ved ikke kun at være et udtryk for menneskeligt overskud, men snarere en nødvendig overlevelsesstrategi i den forfærdelige sorg over at miste et barn.

Med empirisk udgangspunkt i orgando- 
nation og med fokus på moderskabets dynamik og potentiale, diskuterer artiklen nogle af de sociale implikationer ved at have doneret et barns organer. Her fokuseres på en organisatorisk styret måde at italesætte tabet, og en særlig måde at indgå i sociale relationer i organ-organisatorisk regi. Gennem denne analyse udfolder artiklen, hvordan nye udvidede opfattelser og praktiseringer af moderskab bliver en væsentlig strategi i forsøget på at skabe mening med barnets tragiske dødsfald. Under betegnelsen "donormor", bliver praktiseringen af dette partikulære moderskab et kønnet organisatorisk ideal for både mænd og kvinders sorgproces, og det diskuteres derfor også, hvordan mænd har mulighed for at agere i denne kvindedominerede kontekst. Gennem et antropologisk perspektiv på organdonation, gives således en ny optik på, hvorledes køn og moderskab udspiller sig i en amerikansk kontekst.

Artiklen bygger på data indsamlet blandt pårørende til organdonorer under fire måneders antropologisk feltarbejde i New York Organ Donor Network, som er den næststørste organ-organisation i USA. Feltarbejdet var primært lokaliseret i deres afdeling for opfølgning til pårørende til organdonorer, hvor alle pårørende gennemgår et toårigt program med telefonisk rådgivning og støtte. Fokus for mit studie er på de pårørendes erfaringer, hvorfor hovedparten af mit datamateriale består af interviews med dem og deraf deres fortællinger om beslutningen om donation og oplevelsen af tiden derefter. Derudover stammer materialet fra organisationens dagligdag, de mange afdelings- og personalemøder og fra talrige konferencer, ceremonier og events omhandlende organdonation og pårørende, såvel i New York som andre steder i USA.

\section{ORGANDONATION I USA}

I USA er der stor organmangel. Næsten 100.000 amerikanere venter på et organ, der kan redde eller forbedre deres liv. Når et barn eller et ungt menneske erklæres hjernedød, gøres der derfor store anstrengelser for at opnå familiens samtykke til organdonation. I New York Organ Donor Network er der ansat særlige medarbejdere, der tager ud til familierne i den akutte situation på sygehuset, og som et resultat af intensiv træning formår at flette spørgsmålet om organdonation ind $\mathrm{i}$ de pårørendes egne fortællinger om deres afdøde familiemedlem. Eksempelvis ved at understrege, at når nu den afdøde "altid gav til hjemløse" og "var meget hjælpsom", så vil "organdonation være $\mathrm{i}$ hans ånd". I overensstemmelse med organisatoriske værdier og idealer, fremstiller disse medarbejdere således organdonation som en unik mulighed for en logisk videreførelse af afdødes gode egenskaber og for at redde andres liv og gøre afdøde til en helt (Jensen 2007).

Men familiernes oplevelse af beslutningen om organdonationen stemmer ikke altid overens med organisationens idealiserede billede af den heroiske død. I den chokerende akutte situation er det både vanskeligt og traumatisk for forældre at sige ja til, at barnet skal på operationsbordet og have sine vitale organer fjernet, da et ja til organdonation for nogen bliver sidestillet med et ja til døden. Dette skyldes manglende overensstemmelse mellem den medicinske definerede død, nemlig hjernedøden, og de pårørendes personlige erfaringer med og opfattelser af døden, nemlig hjertedød. Donormoderen Mona berettede, hvordan hun ikke var overbevist om, at hendes datter "virkelig var død", og at hende og hendes mand i tiden efter havde været bange for, at de selv havde "været medvirkende til at slå datteren ihjel". Denne tvivl er ikke kun forekommende i mit studie. Antropologisk forskning fra både Israel, Europa, Japan og USA viser, at pårørende ikke opfatter hjernedød som "rigtig” død, så længe hjertet slår, barnets hænder stadig er varme, og brystkassen bevæger sig (Alnæs 2001, Ben-David 2005, Lock 2002, Sharp 2006).

Accept af hjernedødskriteriet og dona- 
tion af kroppens dele forudsætter et særligt syn på kroppen som opdelt i hjerne og kropsdele. Denne medicinsk iværksatte opdeling af krop og sjæl kan føres tilbage til den franske filosof Rene Descartes, der med sin dualistiske opdeling i 'body' og 'mind' legitimerede, at kroppen blev et videnskabeligt undersøgelsesfelt, mens sjælen forblev i det teologiske domæne. Det er netop denne Kartesianske opdeling, der giver anledning til medicinsk og kirurgisk intervention i kroppen, og medfører at kropsdele kan forstås som en samling af udskiftelige dele adskilt fra personligheden eller selvet (Joralemon 1995, Scheper-Hughes \& Lock 1987). Der sker således en objektificering af barnet; en slags reducering fra barn til organer. Det afdøde barns kropsdele forvandles uvægerligt om end ubevidst til efterspurgte varer ved pårørendes samtykke til organdonation. I denne proces ligger en moralsk trussel, idet vareliggørelsen af børn ifølge Igor Kopytoff “indikerer de økonomiske princippers invasion af den humane slægtskabsverden" (Kopytoff 2001:271272).

Som følge af den stigende efterspørgsel af kropsdele, den omfattende illegale handel med organer i tredje verdenslande og politiske diskussioner om finansiel kompensation til donorers familie (Brecher 1994, Healy 2006, Scheper-Hughes 1996, 2004), er organdonation i USA mere eller mindre omkranset af markedsmæssige diskussioner, som organ-organisationerne konstant må forholde sig til. Desuden er velfærdsydelser ikke gratis i USA. Et nyt organ koster mellem 100.000 og 300.000 dollars, afhængig af hvilket organ det drejer sig om, modtagerens helbredstilstand, og eventuelle komplikationer; udgifter der ofte dækkes af egne sygeforsikringer. Ligeledes er det heller ikke gratis for pårørende at have deres familiemedlem indlagt på intensivafdelingerne. Organ-organisationerne dækker derfor alle de ekstra udgifter et organdonationsforløb medfører, hvilket ofte bliver misforstået som en 'betaling' for organerne.
For forældrene betyder det helt konkret, at de bliver konfronteret med spørgsmålet om "de fik noget for det", hvilket opfattes dybt krænkende, og derfor søges afværget. Mit materiale viser dog en klar afstandtagen fra disse finansielle aspekter af organdonation. I mine interviews pointerede især kvinderne gentagende gange, at de ikke ønskede at modtage nogen form for økonomisk kompensation. Den mere eller mindre implicitte vareliggørelse af det døde barn kan siges at udfordre kvindens position som “den gode mor", og står i kontrast til kulturelle værdier omkring familie og forældreskab i USA, hvor moderskabet anses som den primære forbindelse til et andet menneske og ideelt set repræsenterer kærlighed og står i modsætning til penge (Taylor 2004, Rothman 2004).

I tiden efter donationen bliver det derfor nødvendigt for organorganisationen at hjælpe kvinderne med at finde en ny måde at være mor på; at omdefinere handlingen fra at have give barnet væk til at være gode mødre i overensstemmelse med både organisatoriske og samfundsmæssige idealer. Denne transformationsproces er dog ikke udelukkende forbeholdt organdonationsfeltet, hvorfor følgende afsnit omhandler reaktioner på markedsmekanismernes indtog i moderskabet. I mit studie udmønter reaktionen sig konkret i en særlig velorganiseret og stærkt kønnet måde at italesætte og fremstille beslutningen på, der ofte ender med at blive inkluderende for kvinder men ekskluderende for mænd.

\section{MENINGSFULD GAVERETORIK OG MORALSK MODERSKAB}

Nyere antropologisk forskning om moderskab i en amerikansk kontekst viser, at moderskab i USA i højere grad defineres ud fra en form for vareliggørelse. Dette kommer især til udtryk i empiriske felter som adoption, surrogatmøde og handicappede børn. Her omtales børn i stigende grad som en efterspurgt vare - og når det gælder handi- 
cappede børn, som en defekt vare (Landsman 1999, 2004, Modell 1999, Ragoné 1999, Rothman 2004). Denne opfattelse skyldes ikke mindst fremkomsten af nye reproduktionsteknologier, der er i stand til at opfylde behovet for (eller efterspørgslen efter) børn hos barnløse par. Ifølge Igor Kopytoff har disse reproduktionsteknologier elimineret grænsen mellem personer og ting, mellem det sociale og det økonomiske (Kopytoff 2004: 271). I en Euro-amerikansk kontekst er det anfægteligt, når der indsniger sig økonomiske markedsmæssige aspekter i familie og slægtskabsforhold. Slægtskabsforhold skal ifølge samfundets normer helst være fri for markedsøkonomisk indblanding, da moderskab, reproduktion og familie er en ikke-kommerciel sfære (Ragoné 1999: 69).

Som en modreaktion mod denne opfattelse, har antropologiske studier vist, at amerikanske kvinder ofte benytter en såkaldt gaveretorik som sproglig strategi til at modsvare og skjule kroppens indtræeden i markedsøkonomien (Layne 1999, Modell 1999, Ragoné 1999, Landsman 2004). Med gaveretorik menes en sprogbrug, hvor ordet gave eller gaverelaterede ord anvendes metaforisk. Helena Ragonés studier af amerikanske surrogatmødre påpeger, at den finansielle belønning for at føde en anden kvindes barn, fjerner kvinden fra det kulturelle ideal om mødre som uselviske og altruistiske og indskriver hende i det 'babymarked' som også kvinder, der adopterer, er en del af. Men ved at omtale børnene som "gaver" og dem selv som givere af "den ultimative kærlighedsgave" på trods af den finansielle kompensation, legitimerer surrogatmødrene ifølge Ragoné, at deres moderskab er tæet forbundet med køb og salg og indskriver sig i gavegivningens sfære af godgørenhed, uselviskhed og altruisme (Joralemon 1995, Ragoné 1999). Ved en retorisk skelnen mellem at sælge babyer og give barnløse par børn, opretholdes en moralsk distinktion mellem varer og gaver, mellem det økonomiske og det sociale.
Samtidig bekæmper mødrene den antagelse, at de er drevet af profit, de tilfører agens og status til deres handlinger, og der sker derfor "en samfundsmæssig legitimering af deres reproduktive arbejde" (Kopytoff 2004, Ragoné 1999: 68,73).

Under mit feltarbejde i New York Organ Donor Networks afdeling for opfølgning til pårørende $\mathrm{i}$ tiden efter organdonationen, oplevede jeg, hvordan personalet gennem deres støttefunktion gav familierne et nyt sprog til at omtale organdonation, hvor gave som metafor var særdeles dominerende. Mit studie peger således på, at samme retoriske bevægelse fra varer til gaver kan siges at gøre sig gxldende blandt donormødre, når de skal have hjælp til at begrunde deres beslutning overfor uforstående, skabe mening med et tragisk dødsfald og legitimere en tilsyneladende uforståelig og brutal beslutning om et kirurgisk indgreb i barnets døde krop.

En dag på kontoret i afdelingen for donorfamilier, pointerede medarbejderen Susan overfor en fortvivlet donormor i telefonen, at den afdøde datters "vidunderlige gave" havde reddet seks liv og hun "var en helt for mange mennesker". Denne særlige anerkendende og meningskabende gaveretorik, Susan her viser, er et led i en større organisatorisk strategi for at forbinde organdonation med generøsitet og næstekærlighed, gøre det til et højere moralsk anliggende og skabe distance til det uetiske kapitalistiske organmarked. Dermed får pårørende et helt nyt vokabularium og en ny referenceramme at forstå beslutningen om organdonation ud fra. Men samtidig făr kvinderne en mulighed for at indgå $\mathrm{i}$ en næsten rituel forvandling fra "mor" til "donormor"; en proces hvor de lærer, at det ikke var forkert at give barnets kropsdele væk, det var en altruistisk og heroisk handling og et eksempel til efterfølgelse (Jensen 2007). Således kan kvinderne gennem den organisatoriske interaktion og gennem aktiv brug af gaveretorikken tilføre deres moderskab en signifikant moralsk værdi. 


\section{SCENEVANT SORG OG TAVSE MÆND}

I løbet af mit feltarbejde erfarede jeg, at det som oftest var kvinderne, der tog imod organisationens tilbud om opfølgning og involvering i frivilligt arbejde. Medarbejderne $i$ afdelingen begrundede dette med, at mænd som oftest var indelukkede og tavse i deres sorgproces. Kvinders involvering i organisationen kan derfor betragtes som en reaktion mod denne hjemlige tavshed og et udtryk for lyst til at kunne fortælle om sit døde barn igen og igen til et lydhørt publikum og indgå i nære sociale fællesskaber og venskaber med kvindelige lidelsesfæller. Denne kønnede forskel i amerikanske pårørendes sorgproces er også beskrevet af antropologen Lesley Sharp, der gennem sine mangeårige studier af organdonation i USA identificerer en indadvendthed og knap så stor lyst til involvering hos sørgende mænd (Sharp 2001, 2006). Som en væsentlig del af den organisatoriske sorgbearbejdning, opfordres kvinderne til at tale om organdonation offentligt, da det ikke kun gavner deres egen sorg, men i høj grad også medvirker til at styrke organisationens ansigt udadtil og organdonation generelt (Jensen 2007). Donormødrene fortalte mig, hvor helende disse foredrag var for dem. En donormor Betty opfattede det sådan, at "folk først var døde, når man holdt op med at tale om dem", hvorfor hendes store involvering $\mathrm{i}$ at tale offentligt kan anses som et forsøg på at trodse døden og holde datteren "i live". Det at tale om organdonation offentligt i organisatorisk regi, var således en måde, hvorpå mødre kunne trodse velmenende venners og familiemedlemmers (også deres egen ægtemands) smertefulde råd om "at komme videre" og give sig selv lov til at være donormor ved at forblive mor i fortællingerne om det afdøde barn.

For de mænd, der foretrak en mere tavs og privat håndtering af dødsfaldet, medførte dette ideal om italesættelse indskrænkede handlingsmuligheder i organisationen. De fleste mænd var kun tilstedeværende i kvindernes fortællinger som en ulidelig tavshed i hjemmet, der bevirkede lysten til kvindernes involvering. Nogle af de tavse mænd blev dog inddraget i det organisatoriske arbejde, men primært hvis noget tungt skulle slæbes, eller der var andre praktiske opgaver, der ikke krævede så stor sproglig udfoldelse. Et fătal af mænd søgte at involvere sig i organisationens opfølgende sorgarbejde, som oftest ved at søge at kopiere kvindelige praksisser. Enkelte mænd talte offentligt ligesom kvinderne, men forsøgte at gøre deres italesættelse af organdonation mere maskulint og lidt mindre personligt udleverende ved at accentuere de heroiske aspekter af organdonation og tydeligt sammenligne med amerikanske helte og terrorangrebene 11. september (Jensen 2007: 49-53). Det gjaldt især donorfaren James, der var en af de eneste involverede fædre $i$ mit studie. I mit interview med ham, fortalte han grædende, at sønnen havde begået selvmord på hans kontor, i hans stol med hans pistol. Men ved offentlige arrangementer handlede James' historier ikke om den smerte, men mere om de over 60 mennesker sønnens organer og væv havde hjulpet, og om sønnens personlige egenskaber, der nu fortsatte i kraft af organdonation. I James familie var det moderen der var tavs, og han udtrykte bekymring over at hun "ikke var i stand til at tale om det", hvilket vidner om, at det kønnede mønster for tale og tavshed ikke altid er ufravigeligt. En enkelt donorfar i mit studie valgte at være aktiv ved at gå imod organisationens praksisser og konstant foreslå nye måder at støtte pårørende på. Han var langt fra tavs, men han var ikke talende på den 'korrekte' organisatoriske måde. Overfor mig, udtrykte han mistro overfor afdelingens kvindelige ledelse og kunne ikke forstå, hvorfor hans tilbud om involvering ikke blev imødekommet. Et spørgsmål jeg godt kendte svaret på, som følge af min tætte interaktion med afdelingschefen og overværelsen af hendes gentagende strategiske afvisninger af hans forslag, som hun opfattede som en direkte kritik, samt hendes iværksatte snak med an- 
dre donormødre om denne mands drikkevaner. Der ligger således ikke kun en kønnet praksis, men også en kønnet magt i organisationens opfølgningsarbejde, der medvirker til at bevare kvindernes indarbejdede rutiner og fungerer både som inkluderende og ekskluderende faktor. Den kvindelige organisatoriske dominans bliver dog endnu tydeligere, når der stilles skarpt på de mange sociale forhold, organdonation afstedkommer. Her spiller ideer om slægtskab og særlig moderskabet en væsentlig rolle.

\section{Nye MODERSKABER - SLÆGTSKAB GENNEM ORGANDONATION}

Antropologiske studier af organdonation fra USA og Europa viser, at forestillinger om slægtskab ofte iværksættes mellem givere og modtagere, når individerne er kropsligt forbundet gennem en delt biologisk substans som et organ (Alnæs 2001, 2001a, Fox \& Swazey 1992, Sharp 1995, 2006). Et centralt element af organdonations 'slægtskab', er kvindernes følelse af at være 'mor' til modtagerne af barnets organer. Mit studie viste, at kvinder føler, at de nu deler substans med organmodtagerne, og de har desuden noget til fælles, da de selv har "båret rundt på" disse kropsdele under graviditeten. Ligesom mødrene gav liv, da de fødte donor, har de således nu igen "givet liv" til organmodtagerne, der for manges vedkommende føler sig "genfødte" når de transplanteres og fejrer deres "transplantations-fødselsdag". Organmodtagerne opfattes således af mange donormødre som et omvandrende bevis på, at vitale kropsdele fra barnet stadig er "i live" og kan derfor siges at fungere som et kropsligt minde om barnet, der signalerer udødelighed og derfor virker lindrende i mødrenes sorg (Jensen 2007). Donormoren Josie fortalte, hvordan hun havde stor glæde af at mødes med Robert, den afdøde søns nyremodtager. "Han er en del af vores familie nu", fortalte hun, men understregede samtidig, at hun ikke betragtede Robert som en er- statning for sønnen, mere som et meget nært familiemedlem. I mange tilfælde tog Josie dog en slags moderrolle for Robert. Hun hjalp og støttede ham i personlige problemstillinger, de ringede sammen når der var noget nyt, hun værdsatte at han lige "gav lyd fra sig", når han var kommet godt hjem efter et besøg hos dem, og hun var ligeledes var dybt bekymret for ham under Katrina-orkanen, der ramte tæet på hans hus. Via en direkte eller indirekte kontakt til organmodtagerne skaber kvinderne således muligheder for at føle eller agere 'mor' på nye strategiske måde som 'donormor', der i dynamikken mellem at fastholde mindet om det afdøde barn og få et nyt "familiemedlem" hjælper dem i sorgen.

Som en ny tilføjelse til studierne af slægtskab omkring organdonation, viste mit studie dog også, at moderskab rækker ud over forholdet mellem donors familie og organernes specifikke modtagere. Netop fordi at organdonation af mange opfattes som en donation af selve livet, er der blandt de fleste donorfamilier og organmodtagere mere fokus på donationen som handling end donationen af en specifik kropsdel. En donormor kan ikke kun opfattes og føle sig som 'mor' til sit barns organmodtagere, men til alverdens organmodtagere, hvilket udvider moderskabets dimension og potentiale. Sue, der havde mistet sin teenagedatter, fortalte, hvordan hun og manden var blevet "adopteret" af lungemodtageren Bob, der ikke havde kunnet fă kontakt med hans donorfamilie men havde stort behov for at sige tak. Så nu havde de to familier et nært forhold, Sue var Bobs donormor, og Bob gik rundt med en T-shirt med et billede af datteren, fordi han opfattede hende som hans "spirituelle donor". Denne opfattelse af moderskabet har betydning for kvindernes sociale relationer i denne kontekst. Donormoren Betty forklarede, hvordan hun altid følte sig velkommen i en lokal forening for organmodtagere, fordi det var "som om de alle havde min datters organer og jeg var deres donormor”. På den måde 
fik Betty en særlig status som billede på alle donorfamilier og genstand for organmodtagernes taknemmelighed.

Moderskabet i organdonation kan derfor siges at finde analytisk klangbund i både David Schneiders klassiske pointe om kropslig biologisk substans (organerne) som et vigtigt symbol på slægtskab og Janet Carstens nyere ideer om forbundethed baseret på hvorledes slægtskab udtrykkes, praktiseres og erfares (Schneider 1980, Carsten 2000). Som donormor pointeres den kropslige forbindelse fra graviditeten, der i organisationens værdisæt klassificerer moderen som den nærmeste slægtning og berettiger søgen efter "overlevende" kropsdele hos organernes modtagere. Samtidig bliver man også en altomfavnende mor, der kan relatere sig til alle organmodtagere og indgå i sociale relationer til dem med denne særlige form for moderskab som en essentiel faktor. I forhold til moderskabet er faderskabet således skubbet lidt til siden. Mænd optræder primært som partnere til donormødre, snarere end bærere af relationen til organmodtagere. Men denne kønnede praksis er ikke ufravigelig. Hvis faren er den eneste part i forholdet, der er dybt involveret i organisationens aktiviteter, som i eksemplet med James, så overtager han disse moderlige forbindelser til organmodtagerne og modtager samme opmærksomhed, omsorg og anerkendelse, ofte i form af knus og kram og ekstraordinær hensyntagen.

\section{AFsLUTNING: UNISEX MODERSKAB - ET ORGANISATORISK IDEAL}

Betegnelsen donormor indbefatter ikke kun at italesætte organdonation som livets gave i offentlige fora og deltage i et organisatoriske (slægts)fællesskaber med organmodtagere. I organisationens regi, bliver 'donormor' samtidig et ideal for, hvordan man opfører sig som sørgende forældre til en organdonor. Her opstår der nære sociale bånd mellem donormødre $\mathrm{i}$ en gensidig forståelse af hinandens erfaringer og en udveksling af deres lidelseshistorier. Dette kan anses som et 'terapeutisk moderskab' der har til formål at bakke hinanden op i sorgen, byde nye donorpårørende velkommen, og vigtigst af alt yde frivilligt arbejde og tale ved organisationens offentlig arrangementer. Donormoren Jessica forklarede, hvorfor organisationens fællesskab af donormødre er gensidigt helende: "Når du sørger, finder du trøst i folk der har gennemlevet det samme. Her kan man grine og grxde, man kan gøre, som man vil og være sig selv, for her ved de andre, at man altid vil sørge indvendigt". I dette særlige fællesskab er der en klar opfattelse af "generation". De rutinerede donormødre hjælper de nye i deres sorg og bliver med kvindernes egne ord et forbillede og en slags "mor for dem". Donormødrene omtaler sig selv om en "sørgende familie" og prioriterer ofte denne nye familie højere end deres egen familie, hvor de ikke føler deres tidskrævende sorgarbejde er accepteret. I dette terapeutiske fællesskab kan kvinderne således konstant bekræfte deres moderskab til donor og bevare rollen som mor på trods af dødsfaldet, samtidig med at de fungerer som en slags "mødre" for hinanden.

Hvis mænd vil finde fodfæste i dette fællesskab, må det ske på kvindernes præmisser og ud fra deres sociale praksisser. Eksempelvis er et af organisationens vigtigste aktiviteter, administrationen af et såkaldt "Memory Quilt", et minde-quilttxppe, hvor pårørende, primært kvinder, kan konstruere et nøje afmålt "square" til at sætte på det fælles tæppe for at mindes den afdøde. En donorfar Charles var også med til at administrere tæppet, men havde sørget for at der på hans søns firkant var et billede af dem begge iført flyvevåbenets uniform som et forsøg på at maskulinisere dette kvindelige tiltag. På den måde tvinges mænd til at "agere mødre", hvis de vil være en del af organisationens fælles praksisser og må kæmpe for at lægge en maskulin vinkel på fællesskabet. Ofte gøres det som her ved at 
indføre maskuline symboler i både fortællinger og særlige mindeobjekter, men også socialt ved at lave sjov med donormødre og have en ironisk distance til sig selv, sådan at de bliver entertaineren i fællesskabet.

I andre tilfælde søger mændene at efterligne kvindernes nære kropslige forbindelse til donor, der konstant bliver påpeget i organisationen, nogle ved at understrege hvor meget det afdøde barn lignede dem og andre på en mere bogstavelig måde. Donorfaren James fortalte, at han havde haft voldsomme problemer med sin rygsøjle og havde behov for at fà en knogledel fra en donor indopereret i sin rygrad. I hvad jeg anser som et forsøg på at opnå en stærk kropslig forbindelse til sin afdøde søn, opsporede han den væevsbank, hvor sønnens knogledele var lagret, men fandt ud af at alle delene var brugt, og han måtte opgive at "bære sønnen i sig”. Faderen søger altså at etablere en konkret kropslig relation til sønnen, som ellers har været forbeholdt kvinderne. I bitter erkendelse over, at dette ikke kunne lade sig gøre, valgte James i stedet at se det positive aspekt i denne situation og indlemme det i sin offentlig fortælling som en faderlig stolthed over at sønnens kropsdele var "så gode, at de var revet væk".

Artiklen har vist, at moderskab i forhold til organdonation kan siges at være en kompleks proces af forskellige sociale relationer, der praktiseres i den organisatoriske kontekst og bliver meningsskabende for mange mødre (og nogle fædre) i deres sorgproces. Mødrene møder gennem interaktion med organisationen forståelse for deres situation og får muligheden for at forblive sørgende mødre til deres afdøde barn gennem gentagende gange at fortælle deres historie og udtrykke deres sorg både blandt lidelsesfæller og i offentlige fora. Samtidig bliver de mødre på mange andre niveauer; for egne og andre organmodtagere, andre donorfamilier og i et større lokalt, nationalt og globalt organdonationsfællesskab, hvor de anses som moralske og næstekærlige forbille- der (Jensen 2007: 90). Dette bibringer nye forståelser af amerikanske forståelser af køn og moderskab. Men selv om hele organ-organisationens værdisæt omkring italesættelse af sorgen og om særlige måder at indgå i sociale relationer er stærkt domineret af kvinder og hylder moderskabet som ideal, så finder nogle mænd alligevel små smutveje eller omfortolkninger af dette 'unisex moderskab'. Mit studie viser, at det stort set er umuligt for mænd at komme igennem med nye praksisser omkring opfølgning og sorgbearbejdning, men ved at deltage kreativt i de eksisterende organisatoriske aktiviteter, formår nogle mænd alligevel at få en hjælp til sorgen over at miste et barn og indgå i organisationens kvindedominerede sociale netværk.

\section{LITTERATUR}

- Alnæs, Anne Hambro (2001): Minding Matter. Organ Donation and Medical Modernitys difficult Decisions. The Faculty of Social Sciences, University of Oslo.

- Brecher, Bob (1994): Organs for transplant - donation or payment?, i R. Gillion (red): Principles of Health Care Ethics. Wiley, New York.

- Carsten, Janet (2000): Cultures of Relatedness. New approaches to the Study of Kinship. Cambridge University Press, Cambridge.

- Fox, Renee \& Swazey, Judith P (1992): Spare Parts: Organ Replacement in American Society. Oxford University Press, Oxford.

- Healy, Kieran (2006): Last Best Gifts. Altruism and the Market for Human Organs. The University of Chicago Press, Chicago.

- Jensen, Anja Marie (2007): Those Who Give and Grieve - an Anthropological Study of American Donor Families. Institut for Antropologi, Københavns Universitet.

- Joralemon, Donald (1995): $\quad$ Organ wars: the battle for body parts, i Medical Anthropology Quarterly 1995/9.

- Kopytoff, Igor (2004): Commoditizing Kinship in America, i Janelle S. Taylor, Linda Layne \& Danielle F. Wozniak (red): Consuming Motherhood. Rutgers University Press, New Jersey.

- Landsman, Gail (1999): Does God Give Special Kids to Special Parents? Personhood and the Child 
with Disabilities as gift and as giver, i Linda Layne (red): Transformative Motherhood. On Giving and Getting in a Consumer Culture. New York University Press, New York.

- Landsman, Gail (2004): Too Bad You Got a

Lemon: Peter Singer, Mothers of Children with

Disabilities and the Crtique of Consumer Culture, i Janelle S. Taylor, Linda Layne \& Danielle F.

Wozniak (red): Consuming Motherhood. Rutgers

University Press, New Jersey

- Layne, Linda (1999): The Child as a Gift. New directions in the Study of Euro-American Gift exchange, i Linda Layne (red): Transformative Motherhood. On Giving and Getting in a Consumer Culture. New York University Press, New York.

- Lock, Margaret (2002): Twice Dead: Organ

Transplantation and the Reinvention of Death.

University of California Press, Berkeley.

- Modell, Judith S. (1999): Freely Given: Open

Adoption and the Rhetoric of the Gift, i Linda

Layne (red): Transformative Motherhood. On Giv-

ing and Getting in a Consumer Culture. New York

University Press, New York.

- Ragoné, Hélena (1999): Surrogate Motherhood, Gamete Donation and Constructions of Altruism, i Linda Layne (red): Transformative Motherhood.

On Giving and Getting in a Consumer Culture.

New York University Press, New York.

- Rothman, Barbara Katz (2004): Motherhood under Capitalism, i Janelle S. Taylor, Linda Layne \&

Danielle F. Wozniak (red): Consuming Motherhood.

Rutgers University Press, New Jersey

- Scheper-Hughes, Nancy \& Lock, Margaret

(1987): The Mindful Body: A Prolegomenon to

Future Work in Medical Anthropology, i Medical

Anthropology Quarterly 1987/1.

- Scheper-Hughes, Nancy (1996): Theft of Life:

Organ Stealing Rumours, in Anthropology Today, 1996/12(3).

- Scheper-Hughes, Nancy (2004): Parts Unknown, in Ethnography, 2005/5(1).

- Schneider, David (1980): American Kinship. A

Cultural Account. The University of Chicago

Press, Chicago.

- Sharp, Lesley A. (1995): Organ Transplantation as a Transformative Experience: Anthropological insights into the Restructuring of the Self, i Medical Anthropology Quarterly 1995/9(3).

- Sharp, Lesley A. (2001): Commodified Kin:

Death, Mourning and Competing Claims on the bodies of Organ Donors in the United States, i American Anthropologist 2001/103(1).

- Sharp, Lesley A. (2006): Strange Harvest: Organ Transplants, Denatured Bodies and the Transformed Self. University of California Press, Berkeley.

- Taylor, Janelle S. (2004) Introduction, Janelle S. Taylor, Linda Layne \& Danielle F. Wozniak (red): Consuming Motherhood. Rutgers University Press, New Jersey.

\section{SUMMARY}

Dead children as "the gift of life". Unisex motherhood and organ donation in America

The focus of this article is how American women, especially mothers of organ donors dominate organizational support efforts for donor families, the implications this has for men, and the many new understandings of motherhood this medical context gives rise to. Based on anthropological field studies from the US, this article analyses the efforts of American organ organizations to support and comfort families in the time after the organ donation and explores the limited options for men to engage in this interaction, except by acting like 'mothers'. By exploring how women speak about donation and engage in many different social relations to organ recipients and others, this article give rise to new perceptions of motherhood and discusses how gender is acted out in this particular field.

Anja Marie Bornø Jensen, Ph.d. Stipendiat ved Institut for Antropologi, Københavns Universitet 